\title{
Quantitative Comparison of Drainage after Primary Breast Surgery with and Without Drains
}

\author{
Breytenbach JM,* Jandera V \\ Sefako Makgatho Health Sciences, Netcare Krugersdorp Hospital, South Africa
}

\begin{abstract}
Background: No quantitative study has been done to study the fluid drainage with and without drains after breast reduction surgery. Closed suction drainage exerts a considerable amount of pressure on tissues and might increase drainage. Therefore, this study aimed to comparethe effect on breast reduction surgery of closed suction drainage with no drainage.
\end{abstract}

Methods: A group of 12 female patients underwent breast reduction surgery. A drain was placed in the right breast and no drain in the left breast. The drain fluid volume in the right breast was the amount drained plus that detected by sonar until the drained mount was $\leq 30 \mathrm{ml} / 24 \mathrm{hrs}$. The residual volume in the left breast was detected by sonar only.

Results: The mass of tissue removed ranged from $820 \mathrm{~g}$ to $2250 \mathrm{~g}$ in the right breast and from $760 \mathrm{~g}$ to $2240 \mathrm{~g}$ in the left breast. The volume of fluid in the right breast ranged from $24-423 \mathrm{ml}$ and in the left, $7-127 \mathrm{ml}$. The residual volume in the left breast was found to be always less than $30 \mathrm{ml} / 24 \mathrm{hrs}$ and was 8 times less than in the right breast, which had the drain. There was no correlation between the fluid volume and mass of tissue excised.

Conclusion: Within the limitation of the small number of patients, it can be concluded that closed suction drainage can be omitted in large breast reductions without extra complications, and that the amount of residual fluid can be considerably reduced.

Keywords: Breast Reduction Surgery, Closed Suction Drainage, Residual Fluid

\section{Introduction and Literature Review}

Breast reduction surgery is performed on females with macromastia (MM), which is defined as breast tissue in excess of $1000 \mathrm{~g} .{ }^{1}$ Breast reduction surgery is differentiated from mastopexy by the amount of breast tissue removed, which entails removal of no more than $300 \mathrm{~g}$ of breast tissue per breast. ${ }^{2}$ Mastopexy augmentation augments the volume of the breast. ${ }^{3}$ All three procedures create considerable dead space and are commonly performed together with closed suction drains. to eliminate dead space and to prevent complications like seroma formation, hematoma formation, wound healing complications and nipple loss. ${ }^{4,5}$ The drains were initially believed to prevent hematoma formation by draining all the excess blood from the resection cavity. ${ }^{6}$ This theory has been disputed, because even though a drain is inserted into the breast resection cavity, it may not prevent hematoma formation, due to blockage of the drain pipe which can still allow a hematoma to form. ${ }^{7}$

There is evidence in the literature that drain usage in primary breast surgery may not be necessary. Arrowsmith, et al. (1999) ${ }^{7}$ performed breast reduction surgery on 50 patients, Matarasso, et al. $(1999)^{8}$ did the same, Vandeweyer $(2003)^{9}$ had 35 patients enrolled, Wrye, et al. (2003) ${ }^{6}$ enrolled 49 patients, and Collis, et al. $(2005)^{5}$ enrolled 150 patients into their study. These studies all concluded that drains did not prevent hematoma formations, but were often a tract for infection, and patients did not succumb to any extra complications such as wound healing complications, fat

\begin{tabular}{|l|l|} 
Quick Response Code: & *Corresponding author: Jonel May Breytenbach, Sefako Makgatho Health Sciences, Netcare \\
Krugersdorp Hospital, Krugersdorp, South Africa \\
Received: 10 December, 2020 \\
Citation: Breytenbach JM, Jandera V. Quantitative Comparison of Drainage after Primary Breast \\
Surgery with and Without Drains. Mod Res Plast Recon Sur. 2020;1(1):1-4. D0I: 10.53902/MR- \\
PRS.2020.01.000502
\end{tabular}


necrosis or esthetic related issues, by omitting drains. Patients did, however, report better comfort by omitting drains, as well as less anxiety when removing them.

The use of drains in primary breast surgery has also been shown not to be necessary by comparing complication rates when one breast was drained and the other breast was left without a drain. ${ }^{4,5,7,10}$ So far no study has been carried out on patients having primary breast surgery, where one breast is drained and the other is not drained, by quantifying the efficacy of the drain after it was emptied, by means of sonar. Sonar detects the presence of clinically undetectable collections so that comparisons between drained and undrained breasts can be made. This would enable a determination of whether subclinical collections left in the undrained breast would have a significant effect on wound healing or complication rate. The use of sonar would also allow for follow up evaluations to determine when these collections become absorbed.

\section{Material and Methods \\ Ethical clearance}

This study was approved by the Institutional Research and Ethics Committee and the Hospital management (clearance number SMUREC/M/20/2016:PG). The patients' names and study numbers were only available to the primary researcher. All patients who entered the study were given a patient information sheet explaining the procedures and they were given the option to participate at their own free will. They were also able to leave the study any time if they did not wish to participate further. Thereafter each patient signed informed consent. The patients were not remunerated for participating in the study.

\section{Study Population}

The study was a prospective study on consecutively sampled female patients who qualified for primary breast reduction surgery over a one-year period. All female patients undergoing bilateral primary breast reduction surgery were given the option to be included in the study, unless they were on anti-thrombolytic treatment, or were receiving anti-platelet therapy.

\section{Procedure}

Surgery consisted of general anesthesia with preoperative infiltration of both breasts with a vasoconstrictive agent to limit blood loss and contribute to analgesia. The infiltration solution used was one ampoule of adrenalin and $40 \mathrm{ml}$ of $2 \%$ lidocaine mixed into 1 liter of Ringers Lactate, and each breast was infiltrated with 100 $\mathrm{ml}$ of this solution. The breast reduction was performed with a Wise pattern keyhole incision; in half the patients the inferior pedicle technique was used and the supero-medial pedicle was performed in the other half. A closed suction drain was placed in the right breast and no drain was placed in the left breast. The drain used was a closed suction portovac $1 / 4$-inch drain. A routine soft dressing was applied consisting of Ortho-wool and Elastoplast to the chest area post-operatively. All patients received a single dose of Cefazolin $2 \mathrm{~g}$ intra-operatively (or Clindamycin $1.2 \mathrm{~g}$ if allergic to penicillin) and Augmentin 1.2g twice a day for 5 days after the surgery. The patients were monitored for total fluid volume out- put from both breasts on days 1-4 until the closed suction drainage was removed. For the right breast the drain was emptied into a measuring jug every 24 hours and measured using a $20 \mathrm{ml}$ syringe. The breast was also monitored by sonar (Phillips Epic 5 High end Ultrasound) after the drain was emptied. The sonar measurement was performed by the consultant radiologist, and the volume of fluid was calculated by adding the sum of all collections detected by sonar. These measurements were then added to give a total volume output from the right breast on the specific day recorded. The left breast was only measured by means of sonar. Once the closed suction drain had drained less than $30 \mathrm{ml}$ per 24 hours the drain was removed from the right breast. All patients attended follow up visits on days 7, 14, 21 and then 3 months to evaluate with sonar any subclinical collections remaining in the breasts. The follow up visits not only consisted of sonar measurements of fluid collections, but also monitoring for any complications.

\section{Sample size}

Sample size estimation was based on the comparison between fluid volume recorded between right and left breasts i.e. between the two methods. This required the use of a paired-sample t-test. For the detection of small, medium and large effect sizes $(\mathrm{dz}=0.2$, 0.5 and 0.8 respectively), with $80 \%$ power at the $5 \%$ significance level, sample sizes of 199,34 and 15 respectively are required. ${ }^{11}$ Although the aim should be for the detection of at least a medium effect size, should it exist, the actual sample size of 12 in this study would be sufficient only for the detection of very large effect sizes $[\mathrm{dz}=0.9]$; this is a limitation of the study.

\section{Data analysis}

Comparisons of weight removed and fluid volume recorded, between right and a left breast was carried out using the paired samples t-test. The association between volume of fluid recorded and age, weight of breast removed (for each drainage method) was assessed using Spearman's correlation coefficient as the data were not normally distributed. Data analysis was carried out using SAS version 9.4 for Windows. The 5\% significance level was used.

\section{Results}

The study population comprised 12 sequentially sampled female patients aged 18 to 61 years with a median age of 31 years (interquartile range (IQR) 26 - 34 years). The median mass of tissue removed, the range, and comparison between sides is shown in Table 1. There was no statistically significant difference between the sides ( $\mathrm{p}=0.67)$; the mean difference was $16.7 \mathrm{~g}$.

Table 1: Weight of breast tissue removed.

\begin{tabular}{|c|c|c|c|}
\hline Breast & $\begin{array}{c}\text { Median } \\
\text { mass (g) }\end{array}$ & Range (g) & $\begin{array}{c}\text { Paired t-test and Confi- } \\
\text { dence Interval (CI) }\end{array}$ \\
\hline Right & 1430 & $820-2250$ & P = 0.67 \\
\hline Left & 1420 & $760-2240$ & CI -66.0-99.3g \\
\hline
\end{tabular}

Each time the right breast drain was emptied, the total amount of fluid collected through the drain in the right breast was added to the residual fluid measured by means of sonar in milliliters. The left breast was not drained, and the fluid collections were measured 
by sonar and recorded in milliliters. Table 2 shows the volume removed together with the mass of tissue removed, and the age of the patient.

Table 2: Volume of fluid measured (over 3 a months period), mass removed, and age.

\begin{tabular}{|c|c|c|c|c|}
\hline VARIABLE & N & MEDIAN & $\begin{array}{c}\text { Inter-Quar- } \\
\text { tile Range }\end{array}$ & RANGE \\
\hline $\begin{array}{c}\text { Volume of fluid Right } \\
\text { Breast (ml) }\end{array}$ & 12 & 210 & $144-139$ & $24-423$ \\
\hline $\begin{array}{c}\text { Mass removed Right } \\
\text { Breast (g) }\end{array}$ & 12 & 1430 & $1010-2000$ & $820-2250$ \\
\hline $\begin{array}{c}\text { Volume of fluid Left } \\
\text { Breast (ml) }\end{array}$ & 12 & 26 & $13-37$ & $7-127$ \\
\hline $\begin{array}{c}\text { Mass removed Left } \\
\text { Breast (g) }\end{array}$ & 12 & 1420 & $1030-2070$ & $760-2240$ \\
\hline Age of patients (years) & 12 & 31 & $26-34$ & $18-61$ \\
\hline
\end{tabular}

Table 3 Shows the median volume of fluid over the 3-month period and Figure 1 shows this graphically. Although all fluid was resorbed by 3 months, there was an increase recorded on day 14 .

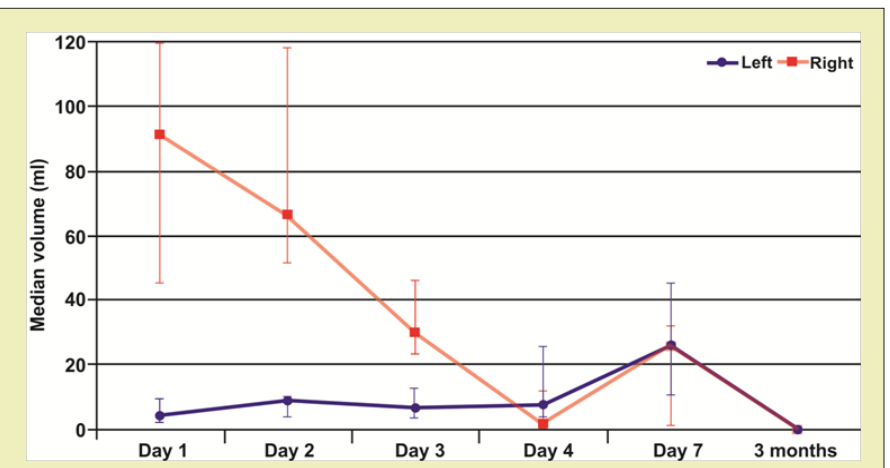

Figure 1: Median volume of fluid over 3 months. Error bars indicate the inter-quartile range.

Table 3: Median volume of fluid over 3 months.

\begin{tabular}{|c|c|c|c|c|c|c|c|}
\hline \multicolumn{2}{|c|}{ BREAST } & DAY 1 & DAY 2 & DAY 3 & DAY 7 & DAY 14 & 3 MONTHS \\
\hline \multirow{2}{*}{ RIGHT } & Median (ml) & 91 & 66 & 29.6 & 1.8 & 25.4 & 0 \\
\cline { 2 - 8 } & IQR (ml) & $45.4-119.2$ & $51.5-118.2$ & $23.5-46.0$ & $0.5-11.9$ & $1.1-32.3$ & 0 \\
\hline \multirow{3}{*}{ LEFT } & Median (ml) & 4.3 & 8.7 & 6.5 & 7.4 & 25.8 & 0 \\
\cline { 2 - 8 } & IQR (ml) & $2.0-9.7$ & $4.0-10.4$ & $3.5-12.9$ & $4.3-25.8$ & $10.9-45.4$ & 0 \\
\hline
\end{tabular}

The association between volume of fluid recorded, age, and mass of breast removed

The right breast showed no significant correlation between volume of fluid recorded and age ( $p=0.13$ ) or mass of breast removed $(p=0.12$ ). The left breast showed significant, positive correlation between the volume of fluid recorded and age $(r=0.71 ; p=0.010)$, but there was no significant correlation between the volume of fluid recorded and the mass of breast removed $(p=0.26)$.

The pedicle technique used had no effect on the amount of dead space or fluid drainage.

\section{Complications}

Two of the twelve patients developed seromas. The first patient developed a seroma on the right breast (which was drained) at day 7: the seroma was resolved with a single aspiration of $18 \mathrm{ml}$. The second patient developed seromas on both breasts at day 9, with bilateral T-junction dehiscence. The seromas were aspirated, dressings were applied and healing was uneventful. No hematomas or infections were observed.

\section{Discussion}

The use of closed suction drainage in breast reduction surgery has continued to be debated in the literature, with many studies reporting that this can be omitted without extra complications. ${ }^{4,6,7,10}$ However, it has also been reported that some plastic surgeons continue to use closed suction drainage as a result of witnessing a large amount of serous-sanguinous fluid draining during the first three days. This was based on the view that the primary purpose of draining breast reduction surgeries was to eliminate complications due to the large dead space that was created, preventing seromas with associated wound complications such as wound dehiscence, infections, and aesthetic complications. . $^{5,12}$

There have been no reports to date, comparing the quantity of fluid retained after breast reduction surgery with and without drainage. This study therefore compared the impact that closed suction drainage had on fluid drainage in bilateral breast reduction surgery compared with no drainage by means of ultrasound detection of residual fluid collections. The study aimed to demonstrate exactly what happens to the fluid collections in the breast that was not drained, and how long it took to be absorbed completely.

A limitation of the study is that the sample size was small and would only be able to detect large effects statistically. Previous studies of breast reduction surgery and the need for closed suction drainage had larger numbers: Arrowsmith, et al. (1999), ${ }^{7}$ Matarasso, et al. (1999), ${ }^{8}$ and Wrye, et al. (2003), ${ }^{6}$ all included 50 patients in their studies, and Collis, et al. $(2005)^{5}$ had the largest study of 150 patients. However, none quantified the volume of fluid in both drained and non-drained breasts, rather being concerned with the complications associated with drainage.

The ages of the patients in this study ranged between 18 and 61 years, and although this was a wide range, 9 of the patients were between 20 and 35 years, with a median age of 31 years and a mean of 33 years. This correlated well with previous studies: Matarasso, et al. (1999) ${ }^{8}$ included patients between 14 to 65 years old, with a mean of 31 years; Vandeweyer (2003) ${ }^{9}$ included patients between 19 - 56 years old with a mean of 35 years; Arrowsmith, et al. $(1999)^{7}$ included patients between ages $18-67$ years; and Collis, et al. $(2005)^{5}$ included patients with ages between $17-64$ years with a mean age of 37 . 
The weight of breast tissue removed in this study was significantly more than previous studies with a median weight of the left breast of $1420 \mathrm{~g}(760-2200 \mathrm{~g})$ and right breast of $1430 \mathrm{~g}(820-$ $2100 \mathrm{~g}$ ). Matarasso, et al. (1999) ${ }^{8}$ reported an average of $476 \mathrm{~g}$ of weight on the right and $477 \mathrm{~g}$ weight on the left. Arrowsmith, et al. $(1999)^{7}$ recorded a mean of $750 \mathrm{~g}$ of breast tissue excised, whereas Wrye, et al. (2003) ${ }^{6}$ excised an average of $675 \mathrm{~g}$ on the drained and $620 \mathrm{~g}$ on the undrained breast. Collis, et al. [6] excised an average of $755 \mathrm{~g}$ on the drained breast and $728 \mathrm{~g}$ on the undrained breast. Vandeweyer $(2003)^{9}$ reported a mean resection of 579g. This study therefore found approximately twice the weight of excised tissue without the use of closed suction drainage and indicates that even though a larger dead space is created it still remains safe to omit closed suction drainage.

The volume of fluid recorded from the drain over the first three to four days was substantial. After the drain was emptied each day the amount of any residual fluid collections detected by ultrasound was added to the amount measured from emptying the drain daily. The median amount of fluid over the first four days in the drained (right) breast was $210 \mathrm{ml}$. The undrained breast was scanned for collections at the same time and the median amount over the first four days was $26 \mathrm{ml}$. Thus with closed suction, 8.1 times more fluid output was produced compared with the breast that was not drained.

In all patients when the drained breast total fluid reduced to $\leq 30 \mathrm{ml} / 24 \mathrm{hrs}$ the drain was removed. In the undrained (left) breast, the fluid recorded was always less than this. At day 14 there was an unexplained increase in fluid measured by sonar, in both breasts, but by 3 months, none showed any residual fluid.

It was not possible to draw any conclusions concerning any associations between volume of fluid drained, age and breast weight excised. The only statistically significant association found was between age and fluid volume in the left breast. There were no significant associations between fluid volume and weight of tissue excised.

\section{Conclusion}

Within the limitations of this study, it can be concluded that omitting closed suction drainage in bilateral breast reduction surgeries can be done safely. By draining a breast reduction with closed suction drainage, the drainage was increased 8 times that when not drained. Closed suction drainage can be omitted in large reductions up to $2200 \mathrm{~g}$ without extra complications of wound de- hiscence or seroma formation. Closed suction drainage can have an irritating effect on breast tissue and seems to cause more drainage. It is recommended that this study should be extended to include larger numbers of patients with a larger variety of ages and more frequent investigations of the breast by means of sonar.

\section{Acknowledgments}

None.

\section{Funding}

None.

\section{Conflicts of Interest}

Author declares that there is no conflict of interest.

\section{References}

1. Chetty V, Ndobe E. Macromastia and gigantomastia: Efficacy of the superomedial pedicle pattern for breast reduction surgery. South African J Surg. 2016; 54(4): 46-50.

2. Hidalgo DA, Spector JA. Mastopexy. Plast Reconstr Surg. 2014; 133(4): 567 e.

3. Spear SL, Dayan JH, Clemens MW. Augmentation Mastopexy. Clinics in Plastic Surgery. 2009; 36: 105-115.

4. Alyssa J. Postoperative Drains in Plastic Surgery: Dispelling the Myths. Plast Reconstr Surg. 2011; 128(4S): 42-43.

5. Collis N, McGuiness CM, Batchelor AG. Drainage in breast reduction surgery: A prospective randomised intra-patient trail. Br J Plast Surg. 2005; 58(3): 286-289.

6. Wrye SW, Banducci DR, Mackay D, Graham WP, Hall WW. Routine drainage is not required in reduction mammaplasty. Plast Reconstr Surg. 2003; 111(1): 113-117.

7. Arrowsmith J, Eltigani E, Krarup K, Varma S. An audit of breast reduction without drains. Br J Plast Surg. 1999; 52(7): 586-590.

8. Matarasso A, Wallach SG, Rankin M. Reevaluating the need for routine drainage in reduction mammaplasty. Plast Reconstr Surg. 1999; 102(6): 1917-1921.

9. Vandeweyer E. Breast reduction mammaplasty shall we drain? ActaChir Belg. 2003; 103(6): 596-598.

10. Kosins AM, Scholz T, Cetinkaya M, Evans GRD. Evidence-Based Value of Subcutaneous Surgical Wound Drainage. Plast Reconstr Surg. 2013; 132(2): 443-450.

11. Faul F, Erdfelder E, Lang AG, Buchner A. G*Power 3: A flexible statistical power analysis program for the social, behavioral, and biomedical sciences. Behav Res Methods. 2007; 39(2): 175-191.

12. Ngan PG, Iqbal HJ, Jayagopal S, Sillitoe AT, Dhital SK, et al. When to use drains in breast reduction surgery?. Ann Plast Surg. 2009; 63(2): 135137. 